\title{
LETTER
}

\section{Outcome measures for manual lung hyperinflation: not there yet!}

\author{
George Ntoumenopoulos* \\ See related research by Paulus et al., http://ccforum.com/content/16/4/R145
}

The recent systematic review by Paulus and colleagues provides an insight into manual lung hyperinflation (MHI) [1], but deserves further comment.

MHI research has generally focused on surrogate measures of secretion clearance, such as lung/thorax compliance [2]. Investigation into the effects of MHI on airway secretion clearance is warranted to elucidate the mechanistic and hence potential therapeutic role.

Volpe and colleagues [3] and Li Bassi and colleagues [4] have reported mechanical ventilation flow-bias thresholds that can move airway secretions both towards (expel) and away (embed) from the mechanical ventilator. These measurement methods may be useful to identify the optimal MHI technique [4]. Van Aswegen and colleagues recently demonstrated that $\mathrm{MHI}$ with a positive endexpiratory pressure of $7.5 \mathrm{cmH}_{2} \mathrm{O}$ in a supine position resulted in a preferential airflow distribution (using technetium-99m) to the right lung as compared with the left lung [5]. Hence, for left lung collapse the combination of patient positioning (for example, lying on the right side) with MHI may both optimise lung recruitment and/ or secretion clearance.

Owing to the requirement for airway disconnection, Paulus and colleagues allude to the potential for MHI to result in airway contamination and cause ventilatorassociated pneumonia [1]. Along similar lines, however, closed suction has often been advocated as a means to prevent ventilator-associated pneumonia (also by preventing circuit disconnection). A recent meta-analysis on closed versus open suction demonstrated no changes in the rates of ventilator-associated pneumonia [6], but closed suction was associated with increased duration of mechanical ventilation and airway contamination. The optimal MHI technique and outcome measures require identification.

\section{Abbreviations}

$\mathrm{MHI}$, manual lung hyperinflation.

\section{Competing interests}

The author declares that he has no competing interests.

Published: 8 November 2012

\section{References}

1. Paulus F, Binnekade JM, Vroom MB, Schultz MJ: Benefits and risks of manual hyperinflation in intubated and mechanically ventilated intensive care unit-patients: a systematic review. Crit Care 2012, 16:R145.

2. Hodgson C, Denehy L, Ntoumenopoulos G, Santamaria J, Carroll S: An investigation of the early effects of manual lung hyperinflation in critically ill patients. Anaesth Intensive Care 2000, 28:255-261.

3. Volpe MS, Adams AB, Amato MB, Marini JJ: Ventilation patterns influence airway secretion movement. Respir Care 2008, 53:1287-1294.

4. Li Bassi G, Saucedo L, Marti JD, Rigol M, Esperatti M, Luque N, Ferrer M, Gabarrus A, Fernandez L, Kolobow T, Torres A: Effects of duty cycle and positive end-expiratory pressure on mucus clearance during mechanical ventilation. Crit Care Med 2012, 40:895-902.

5. Van Aswegen H, Van Aswegen A, Du Raan H, Du Toit R, Spruyt M, Nel R, Maleka M: Airflow distribution with manual hyperinflation as assessed through gamma camera imaging: a crossover randomised trial. Physiotherapy 2012. [http://dx.doi.org/10.1016/j.physio.2012.05.007]

6. Siempos I, Vardakas K, Falagas W: Closed tracheal suction systems for prevention of ventilator-associated pneumonia. Br J Anaesth 2008, 100:299-306.

doi:10.1186/cc11496

Cite this article as: Ntoumenopoulos G: Outcome measures for manual lung hyperinflation: not there yet! Critical Care 2012, 16:457.
*Correspondence: georgentou@yahoo.com

Physiotherapy Department, Guy's and St Thomas'Hospital, Kings Health Partners, London SE1 7EH, UK 